Research Article

\title{
Experimental and Numerical Studies on Rock Cutting with Saw Blade and Conical Pick Combined Cutting Method
}

\author{
Zhenguo Lu $\mathbb{D}$, ${ }^{1}$ Qingliang Zeng $\mathbb{D},{ }^{2}$ Zhiwen Wang $\left(\mathbb{D},{ }^{2}\right.$ Xu Li $\mathbb{D},{ }^{2}$ and Kuidong Gao $\mathbb{D}^{2}$ \\ ${ }^{1}$ College of Transportation, Shandong University of Science and Technology, Qingdao 266590, China \\ ${ }^{2}$ College of Mechanical and Electronic Engineering, Shandong University of Science and Technology, Qingdao 266590, China
}

Correspondence should be addressed to Zhenguo Lu; 13791957893@163.com

Received 29 May 2019; Accepted 14 September 2019; Published 30 October 2019

Academic Editor: Emilio Turco

Copyright ( $\odot 2019$ Zhenguo Lu et al. This is an open access article distributed under the Creative Commons Attribution License, which permits unrestricted use, distribution, and reproduction in any medium, provided the original work is properly cited.

In the rock cutting process, conical pick wear is often encountered. In order to restrain this condition, a saw blades and conical pick combined cutting method was put forward. Saw blades were employed to slit the rock for increasing the free surface, and then the conical pick was used to break the rock. To research the cutting performance of the new cutting method, the corresponding experimental device and a three-dimensional finite element model are established. In order to obtain crack propagation and fragment separation and to study the fracture process of the rock plate, a damage constative model and failure mechanism were combined in the numerical model. The mechanical tests were carried out to achieve the mechanical parameters of the rock. To investigate different parameters affecting rock plate cutting performance, experiments with different compressive strengths, physical parameters, and cutting depths were carried out. Moreover, the confining pressures affecting the cutting performance were adopted to simulate deep mining conditions. The experimental results demonstrated that the peak cutting force shows the exponential positive correlation with compressive strength, thickness of the rock plate, and cutting depth of the conical pick, and exhibits the exponential positive correlation with rock plate height and width. Besides, the numerical simulation results show that peak cutting force and confining pressure have a binomial relationship.

\section{Introduction}

Roadheader is the common equipment in coal mining. In order to improve its hard rock cutting performance and to apply in different engineering requirements, previous scholars have obtained a lot of scientific laws through experimental, numerical simulation, and theoretical research studies. New rock cutting methods and rock breaking mechanisms are very important for predicting rock cutting force and reducing conical pick wear.

Several methods have been applied to rock cutting, such as rock cutting by cutting tools [1], rock cutting assisted by high-pressure water jets [2], rock breaking by thermal energy [3], and rock breaking by microwave irradiation [4]. Combined with the engineering practical application, rock cutting using a mechanical tool was the most used, productive, and reliable cutting method when compared with others. The classic theoretical models for predicting rock cutting forces with conical picks were proposed by Evans
$[5,6]$. The optimized models which considered the friction angle of the rock were proposed by Roxborough and Liu [7] and Goktan [8]. These theoretical models had a great significance in guiding conical pick design. Many experiments have been carried out to research the relationships between different parameters in the process of the conical pick and rock interaction. Balci and Bilgin [9] carried out the experimental and statistical analyses to research the relationship of specific energy between full-scale and smallscale rock cutting tests. The linear cutting experiments were performed to investigate specific energy and cutting force influenced by line spacing and cutting depth $[10,11]$. Niu et al. [12] researched the relationship between cutting force and morphology of fragments by an experimental approach. By comparison between numerical simulation and experiment, a cutting force modeling method was proposed, and the dynamic cutting force and wear of cutter can be obtained $[13,14]$. It is worthy to note that numerical simulation is also an effective method to study rock fragmentation. For specific 
conditions, the numerical simulation method has advantages of faster calculation speed, detailed results, and lower cost compared to experimental and theoretical methods. Huang [15] et al. employed the three-dimensional finite element method (3D FEM) to establish an interaction model between the conical pick and rock under deep mining conditions. By the comparison between experimental, numerical, and theoretical results, the theoretical model was modified considering confining pressure. Li et al. [16, 17] and $\mathrm{Zhu}$ et al. [18] also used the 3D FEM to research the cutting performance of the conical pick, but the mechanism of rock fragmentation has not been mentioned. Park et al. [19] used 3D FEM to study the structural stability and wear of the point attack pick in the rock cutting process. Lu et al. [20] employed ANSYS/LS-DYNA to research the cutting force and fracture morphology in the rock plate cutting process; the cutting position and cutting angle influencing cutting performance were investigated, and the relationship between cutting force and the rock fracture process was given. The satisfactory crack propagation and rock chip separation during rock cutting can be obtained by the twodimensional finite element method (FEM 2D) [21-23], but the cutting force is not close to reality because the rock cutting process is three dimensional. The three-dimensional discrete element method (3D DEM) was employed to study varieties of cutting force processes. It demonstrated that numerical results have a strong relevance with theoretical and experimental results $[24,25]$. However, crack propagation and chip separation were not obviously. Meanwhile, two-dimensional discrete element method (DEM 2D) method is also poor in simulating chip separation [26, 27], although cracks can be obtained. Stavropoulou [28] and Innauratoetal et al. [29] employed finite difference method (FDM) to investigate the chip formation in the rock and cutting tool interaction process and the satisfactory results were achieved. Therefore, the $3 \mathrm{D}$ simulation method is mainly employed to research cutting force, while the $2 \mathrm{D}$ simulation method focuses on the research of crushing mechanism.

Although considerable research studies have been carried out in recent years, there is lack of new rock cutting methods proposed for hard rock cutting. Meanwhile, few studies have been done to simulate the mechanism of crack generation and fragment separation by employing the threedimensional finite element method. In order to improve the cutting ability of the hard rock, the saw blade-conical pick compound rock cutting method was proposed. A 3D FEM which combines damage material and penetration failure is employed to study the fracture process and mechanism of rock. Based on the new rock cutting method, the work of the paper is mainly carried out on the basics of rock plate formation. In this paper, numerical and experimental studies on rock plate cutting were carried out.

\section{Methods}

2.1. Proposal of New Cutting Method. For a traditional roadheader, increasing the cutting power is an effective approach to improve cutting ability, but at the same time, the wear of the pick will increase [30]. Conical pick edge damage and tip separated of roadheader in the traditional roadway excavation are presented in Figures 1(a) and 1(b), respectively.

In order to overcome this problem, the new cutting method of hard rock cutting must be put forward. In stone industry, a diamond saw blade is an effective tool for rock processing, so it can be combined with the conical pick to break hard rock. Diamond saw blades are employed to cut the base rock to obtain rock plates, as illustrated in Figure 2(a). Due to lack of support, strength of rock plates reduced obviously. However, the rock plate obtained by rock slitting is a rectangular chamfer. In the latter study, the chamfer was ignored and the rock plate was regarded rectangular to be convenient for simulation and experiment. In the basics of rock plates formed, rock plates were cut by conical picks, as illustrated in Figure 2(b). Based on the free surface increased cutting method, the roadheader has been manufactured, as shown in Figure 3.

2.2. Experiment. The rock plate cutting test bed, as shown in Figure 4, includes the hydraulic power system, rock cutting components, and signal acquisition system. The rock cutting components are mainly composed of rock plate fix components, sliding guides, and conical picks. The test signal acquisition system consists of a static torque sensor, a transmitter, a signal acquisition device, and a computer. During the rock plate cutting experiment, the voltage signal of the static torque sensor is obtained. The measuring range of the static torque sensor is $0 \sim+3000 \mathrm{~N} \cdot \mathrm{M}$. The maximum sampling frequency of the test signal acquisition system is $1000 \mathrm{kHz}$, and $10 \mathrm{kHz}$ was employed during the experiment. The computer and corresponding software can display, analyze, and process the obtained data.

Rock mechanics parameters are the basis of numerical simulation and experiment. From previous studies, Brazilian tensile strength (BTS) and uniaxial compressive strength (UCS) are the critical parameters influencing cutting performance. Meanwhile, density $(D)$ and elasticity modulus $(G)$ are very important for numerical simulation. The main mechanical properties including BTS, UCS, $D$, and $G$ of rock materials are summarized in Table 1.

2.3. Numerical Model. By comparing and analyzing the advantages and disadvantages of each software, the 3D FEM was employed for modeling the interaction model between the conical pick and rock, as illustrated in Figure 5. In the model, the fixed rock was cut by a moving conical pick.

The selection of the rock constitutive model has a significant influence on numerical simulation. The rock model chosen for investigation must satisfy the requirements: (a) the main properties of rock material must can be set, (b) the rock model needs to satisfied the visualization of crack generation and fragments separation in the rock cutting process, (c) the visualization of cutting process is owned to element deletion caused by tensile or shear failure of rock elements, therefore, the elements of rock model must can be endowed with failure, and (d) at the contact position between the conical pick and 


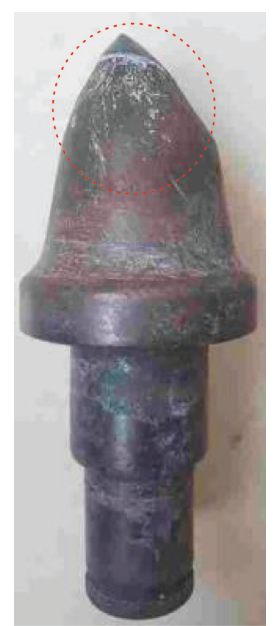

(a)

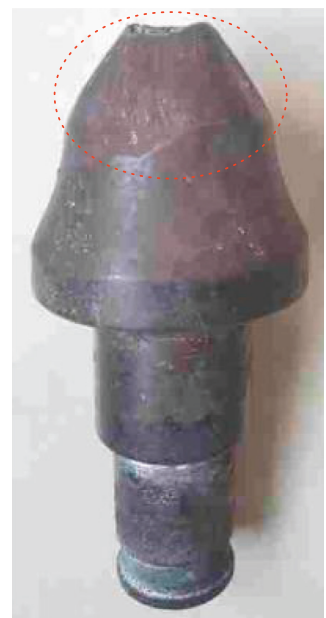

(b)

Figure 1: Pick damage. (a) Pick edge damage and (b) tip separated.

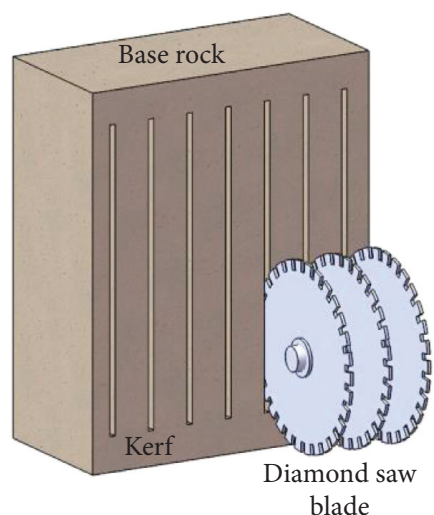

(a)

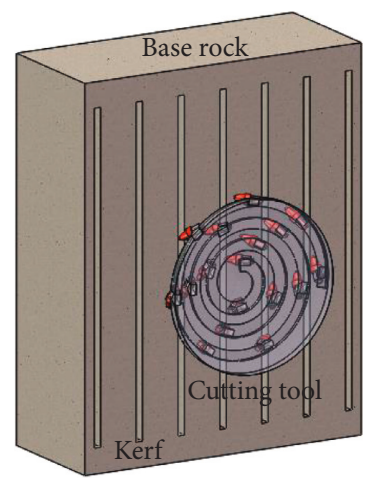

(b)

FIGURE 2: Free surface increased cutting method. (a) Free surface formation and (b) rock plates breaking.

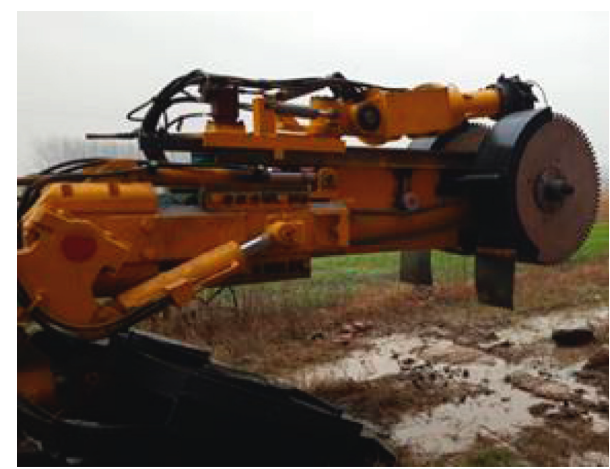

FIgURE 3: The rock cutting device with diamond saw blades and point attack picks combination.

the rock plate, some rock elements will generated compression damage failure, thus, the rock model must contain constitutive damage model. The JOHNSON_HOLMQUIST_CONCRETE (JHC) model mentioned in [31] can satisfy the above requirements. In this paper, rock was assigned by the damage constitutive model JHC [31], which included the compressive damage model and failure. Because tensile and shear failure are not included in the material model, it is necessary to combine penetration failure to simulate rock fracture successfully; therefore, erosion was added in the constitutive model. The rock plate has many important physical parameters, especially the width, thickness, and height, which were denoted by $l_{x}, l_{y}$, and $l_{z}$, as illustrated in Figure 5(a). The $P$ in Figure 5(b) denotes external confining pressure to research external stress influencing cutting performance. To protect the rock fracture characteristic from influence of stress wave, nonreflecting boundary condition was applied on all surfaces of the base rock. To define the base rock is infinite, the symmetric border constraints were added to each surface of the base rock.

\section{Results, Analysis, and Discussion}

3.1. Rock Cutting Process. With the conical pick movement, cutting force was generated between the conical pick and the rock plate. The bending moment and internal force are produced by bending of the rock plate, which leads to cracks on the surface and inside the rock plate, resulting in rock 


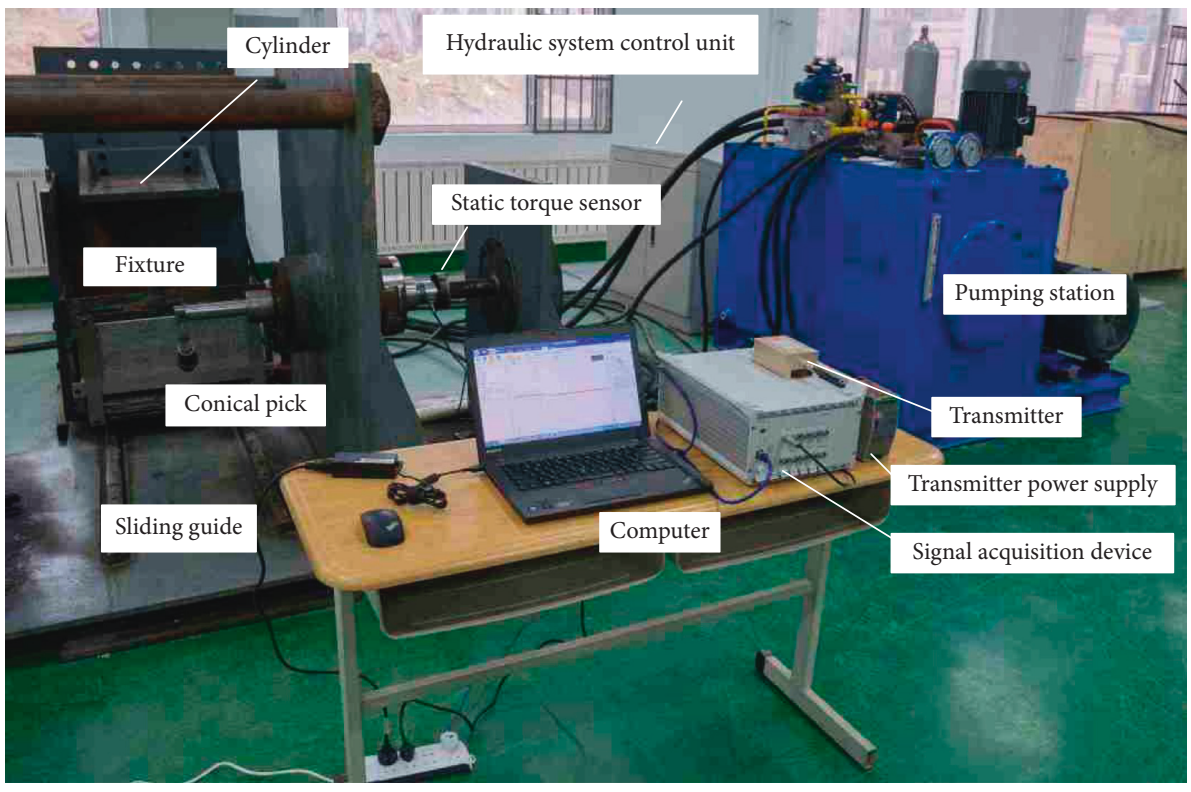

Figure 4: The rock plate cutting test bed.

TABLE 1: The mechanical properties of rock.

\begin{tabular}{lcccc}
\hline Rock & BTS $(\mathrm{MPa})$ & $\mathrm{UCS}(\mathrm{MPa})$ & $\mathrm{G}(\mathrm{GPa})$ & $\mathrm{D}\left(\mathrm{kg} / \mathrm{m}^{3}\right)$ \\
\hline Marble & 5.3 & 43.8 & 52.9 & 2670 \\
Sandstone-1 & 7.9 & 86.4 & 54.5 & 2683 \\
Granite & 12.1 & 120.7 & 45.5 & 2732 \\
Sandstone-2 & 10.6 & 139.1 & 58.3 & 2716 \\
\hline
\end{tabular}

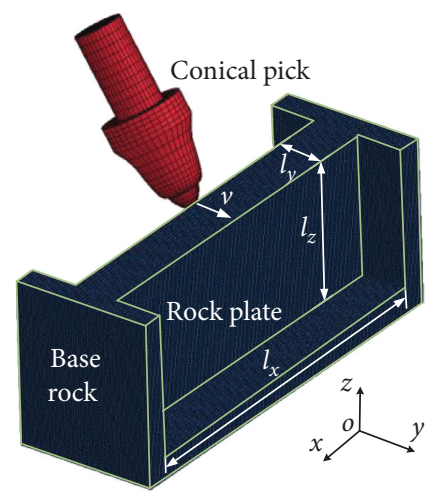

(a)

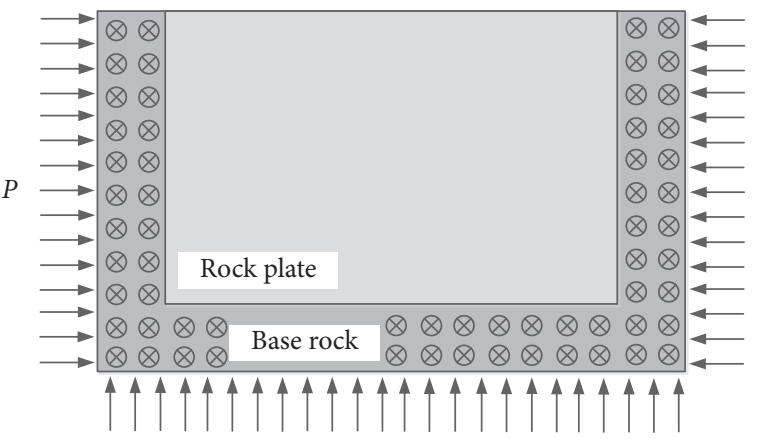

(b)

FIGURE 5: Numerical model. (a) Cutting parameters and (b) confining pressure.

plate fracture. The cutting process of sandstone- 1 with a width of $500 \mathrm{~mm}$, height of $200 \mathrm{~mm}$, and thickness of $20 \mathrm{~mm}$ is shown in Figure 6. In the initial crushing stage, there was small amount of rock elements failure near the rock cutting position, as shown in Figure 6(a). The contact area between the rock and conical pick at this stage is very small, resulting in rock elements generating larger deformation and bearing higher compressive stress. Furthermore, rock elements fail due to compressive damage. When the failure elements were removed from the rock plate, the contact area between the conical pick and rock increased, resulting in higher cutting force generated. With the increasing cutting force, deformation of the rock plate increased and tensile stress increased, and then a main crack was generated from rock cutting position, as illustrated in Figure 6(b). Under the action of bending moment, cracks occurred at the intersection of fixed boundary and free boundary, as illustrated in Figure 6(c). Afterward, more cracks generated from the main crack irregularly with increasing cutting distance, as expressed in Figure 6(d). Thereafter, cracks expanded outward rapidly, longer cracks formed, bottom boundary of rock plate fractured, and more cracks generated, as shown in 


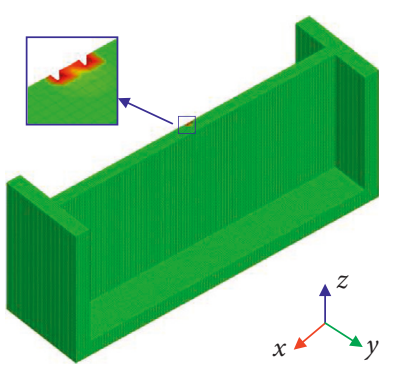

(a)

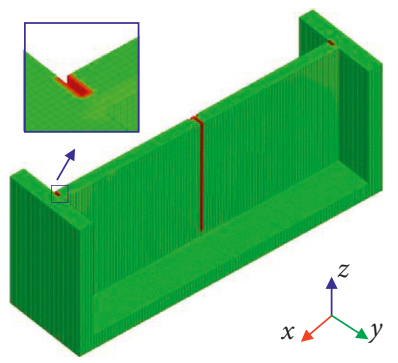

(c)

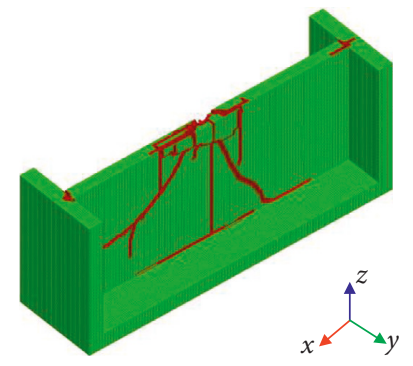

(e)

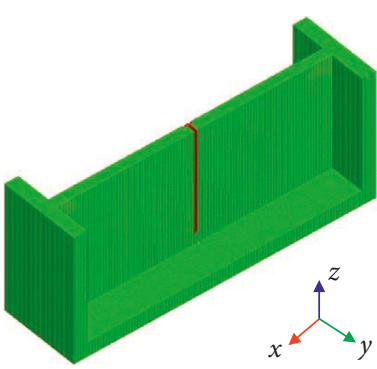

(b)

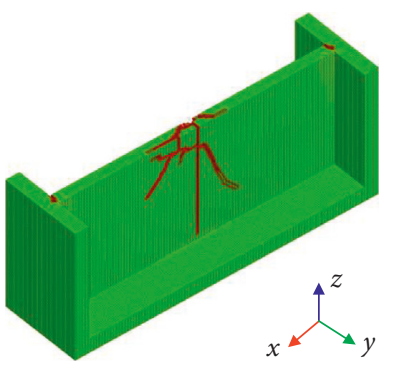

(d)

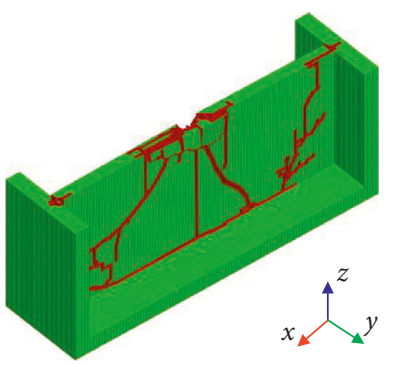

(f)

FiguRE 6: The cutting process of rock plate: (a) compression deformation and failure, (b) main crack formation, (c) boundary fractured, (d) crack propagation, (e) bottom boundary fractured, and (f) crack connection.

Figure 6(e). Finally, cracks contact each other and the rock fragments dissociate from the base rock, as illustrated in Figure 6(f). The variation of cutting force with time is illustrated in Figure 7; with contact between the rock and conical pick, the cutting force increased and reached a maximum of $1.86 \mathrm{kN}$ and then decreased to zero rapidly. In the latter part of the paper, the reliability of numerical peak cutting and fracture morphology will be verified by the experimental method.

3.2. UCS of Rock Influencing Cutting Performance. To study the influence of UCS on rock plate fracture, experiments were carried out with four different rocks such as marble, granite, sandstone-1, and sandstone-2, as presented in Figure 8. The rock plate had a thickness of $20 \mathrm{~mm}$, height of $200 \mathrm{~mm}$, and width of $500 \mathrm{~mm}$, respectively. It is obvious that rock plates were cut to fragments under the action of the conical pick, and the size of fragments increased when compared with the traditional rock cutting method. According to Figure 8, there are two main morphological cracks obtained in rock plate cutting result. One is the radial cracks which extended outward from the cutting position as shown with the blue lines in Figure 8, and the other is close to the circular arc as shown with

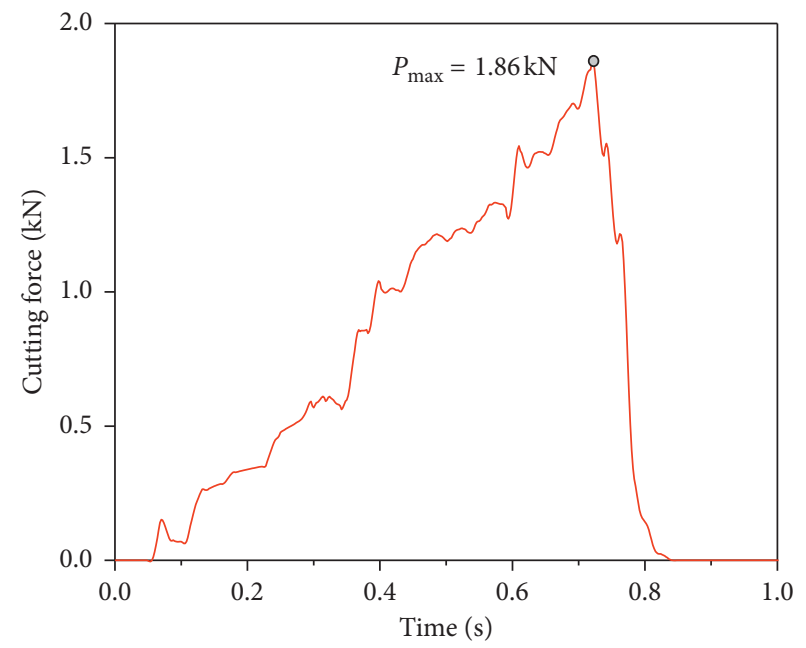

FIGURE 7: Numerical result of cutting force for sandstone-1.

the red line in Figure 8. That is due to the brittle fracture caused by tensile strength which generated on the back of the cutting position. By the cutting results of marble, it is not difficult to find that only partial breakage occurs for rock with 


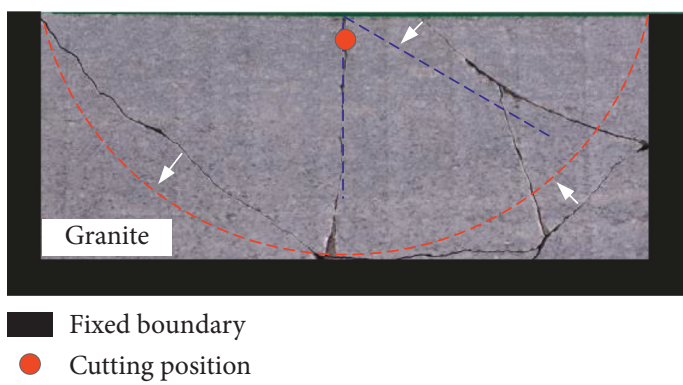

(a)

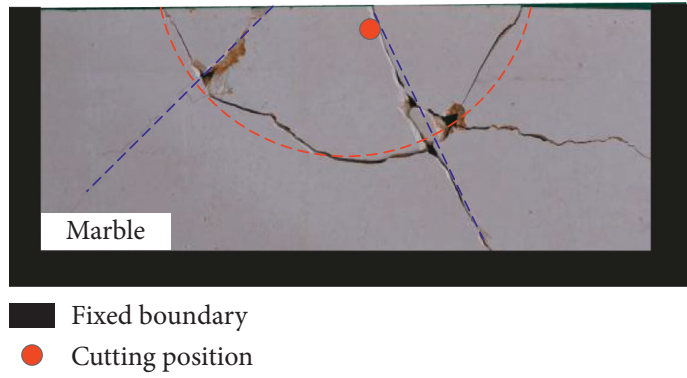

(c)

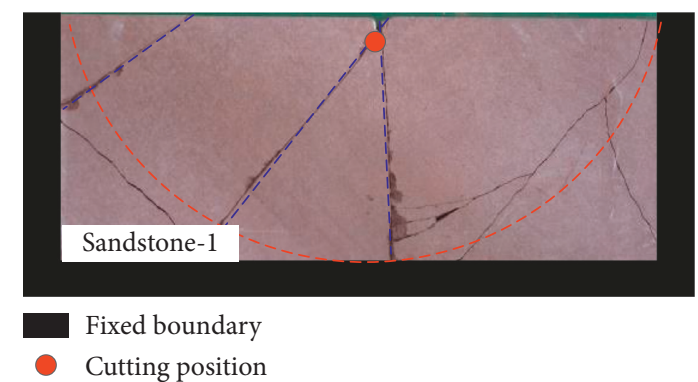

(b)

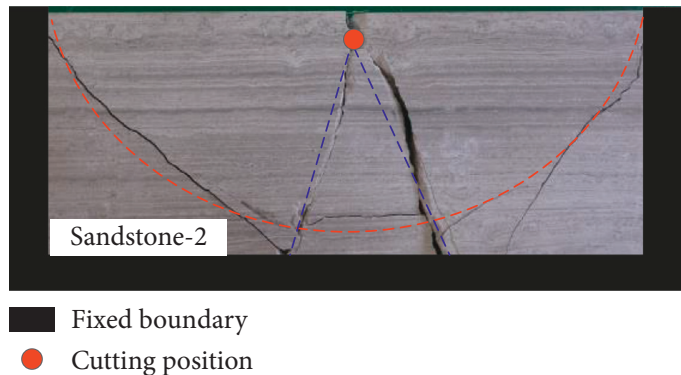

(d)

FIgURE 8: The fracture of rock plates with different mechanical properties: (a) granite, (b) sandstone-1, (c) marble, and (d) sandstone-2.

lower strength, as shown in Figure 8(c). Through comparison, the fracture morphology of sandstone- 1 obtained by experiment, as shown in Figure 8(b), is basically the same as that obtained by numerical simulation, as shown in Figure 6(f). Therefore, the numerical simulation method is reliable to study rock fracture morphology.

The variation of cutting force during rock cutting experiments for the different mechanical properties of rocks is illustrated in Figure 9. Because the rock plate generated deformation during the rock cutting process, cutting force increased with time until the maximum was reached. However, when the rock plate was cut down by the conical pick, the cutting force declined abruptly to zero. It can be seen the cutting force of granite, sandstone- 1 , and sandstone- 2 has fluctuation after the peak cutting force, but the cutting force of marble decreases to zero directly. Therefore, the rock plate with lower compressive strength is more likely to be broken.

To study the mechanical properties influencing cutting force, the peak cutting forces were identified for different rocks as presented in Table 2. Among all rocks, the peak cutting force of marble is the smallest with $1.398 \mathrm{kN}$; meanwhile, the peak cutting force of sandstone- 2 is the biggest with $2.546 \mathrm{kN}$. The peak cutting force of sandstone- 1 is $1.656 \mathrm{kN}$, basically the same with the simulation results; therefore, the simulation result of cutting peak force is reliable. The relationship between peak cutting force and UCS of rock is illustrated in Figure 10. It can be seen from the experimental curve that with the increased compressive strength, the peak cutting forces raised significantly.

3.3. Physical Size of Rock Plate Influencing Cutting Performance. To investigate the width of the rock plate influencing cutting force, experiments were carried out at a

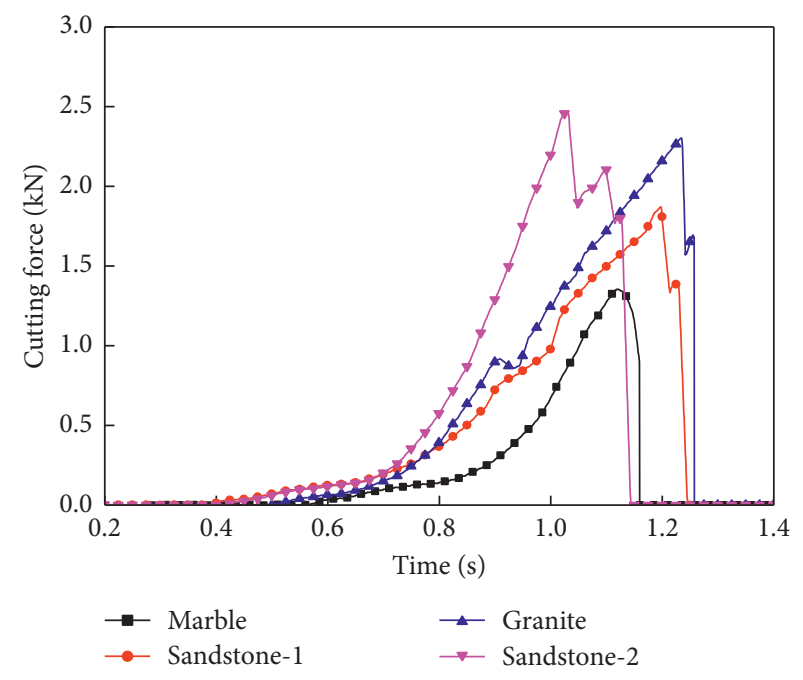

FIGURE 9: The cutting force for rock plates with different mechanical properties.

height of $200 \mathrm{~mm}$, thickness of $20 \mathrm{~mm}$, and widths of $200 \mathrm{~mm}, 300 \mathrm{~mm}, 400 \mathrm{~mm}$, and $500 \mathrm{~mm}$. The cutting results with different widths of the rock plate are presented in Figure 11. It is obvious that the rock plate fractured integrally and the fracture characteristic was the same as that in Figure 8. Therefore, plate width has a little impact on the results of rock fragment. The peak cutting forces are relatively stable at the widths of $300 \mathrm{~mm}$ to $500 \mathrm{~mm}$. However, when the width decreased to $200 \mathrm{~mm}$, peak cutting force increased obviously, as presented in Figure 12. It can be attributed to that when the width of the rock plate decreased, the bending strength increased. In detail, the rock plate was 
TABLE 2: The peak cutting force with different rock mechanical properties of rock plate.

\begin{tabular}{lcccc}
\hline Rock & Marble & Sandstone- & Granite & Sandstone-2 \\
\hline Peak cutting force $(\mathrm{kN})$ & 1.398 & 1.656 & 2.120 & 2.546 \\
\hline
\end{tabular}

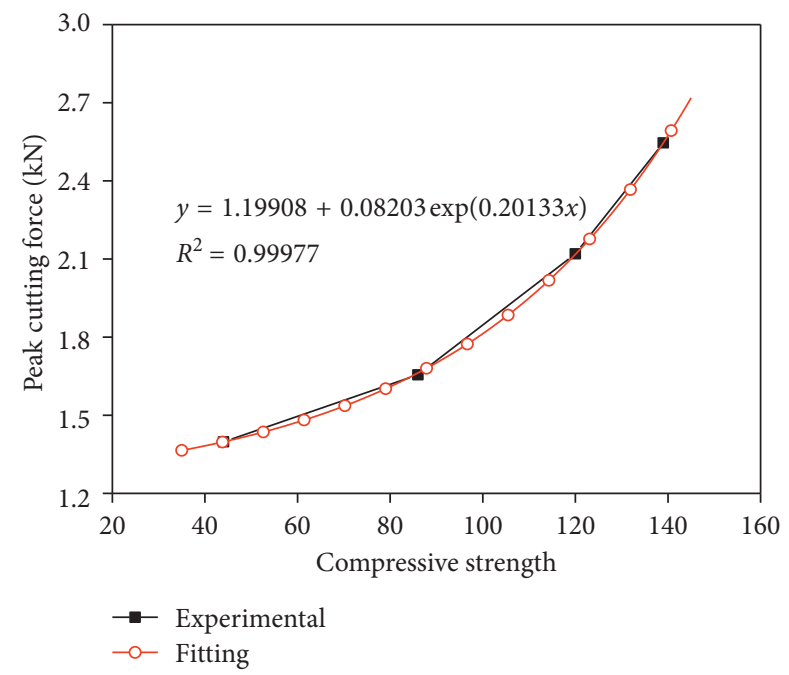

FIGURE 10: Variation of peak cutting forces at different UCS.

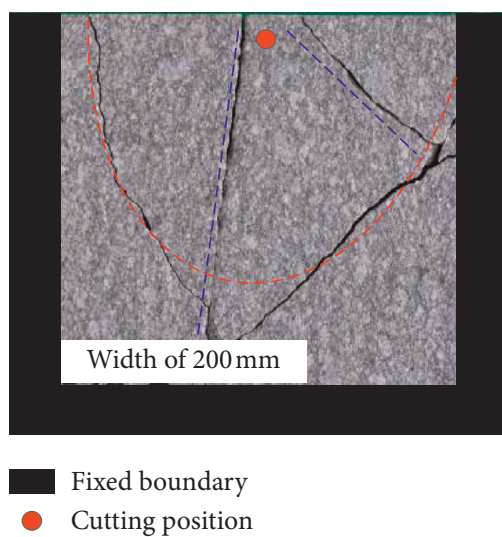

(a)

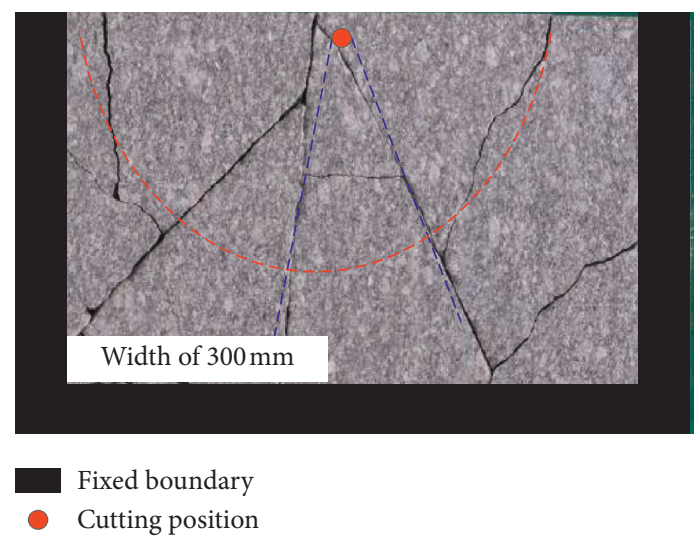

(b)

FIGURE 11: The experimental results for different widths of rock plates: (a) $200 \mathrm{~mm}$ and (b) $300 \mathrm{~mm}$.

hard to deform when the width reduced to a lower level. As a result, the conical pick bore greater resistance.

In general, only at the lower width, the peak cutting force varied greatly. Relatively, at the higher width, the peak cutting force keep stable or change little, as shown in Figure 13. Therefore, in engineering application, it is not necessary to obtain the extremely wide rock plate, as long as it reaches a certain value.

As presented in Figure 14(a), the cutting results at a thickness of $20 \mathrm{~mm}$, height of $160 \mathrm{~mm}$, and width of $500 \mathrm{~mm}$ consistent with Figure 8. However, when the height decreased to $80 \mathrm{~mm}$, as presented in Figure 14(b), the rock fracture morphology obviously differed from that shown in Figure 8. In detail, only half of the rock plate with a height of $80 \mathrm{~mm}$ was fractured and the other half remained on the base rock.
The experimental results of cutting force at a width of $500 \mathrm{~mm}$, thickness of $20 \mathrm{~mm}$, heights of $80 \mathrm{~mm}, 120 \mathrm{~mm}$, $160 \mathrm{~mm}$, and $200 \mathrm{~mm}$ are presented in Figure 15. By comparison, the maximum peak cutting force is acquired at a height of $80 \mathrm{~mm}$ with $2.663 \mathrm{kN}$. For widths of $120 \mathrm{~mm}$, $160 \mathrm{~mm}$, and $200 \mathrm{~mm}$, the peak cutting forces are $2.403 \mathrm{kN}$, $2.166 \mathrm{kN}$, and $2.120 \mathrm{kN}$, respectively. It is due to the higher height of the rock plate, the distance is higher between the conical pick and the bottom of the rock plate. To achieve the same bending moment at the rock plate bottom edge, lower height required higher cutting force. The difference of experimental results between $160 \mathrm{~mm}$ and $200 \mathrm{~mm}$ is very small, almost identical. According to Figure 16, with the raising height, the cutting forces reduced and then tended to be steady. Therefore, the lower height is a disadvantage to rock plate cutting: it obviously increased the cutting force, 


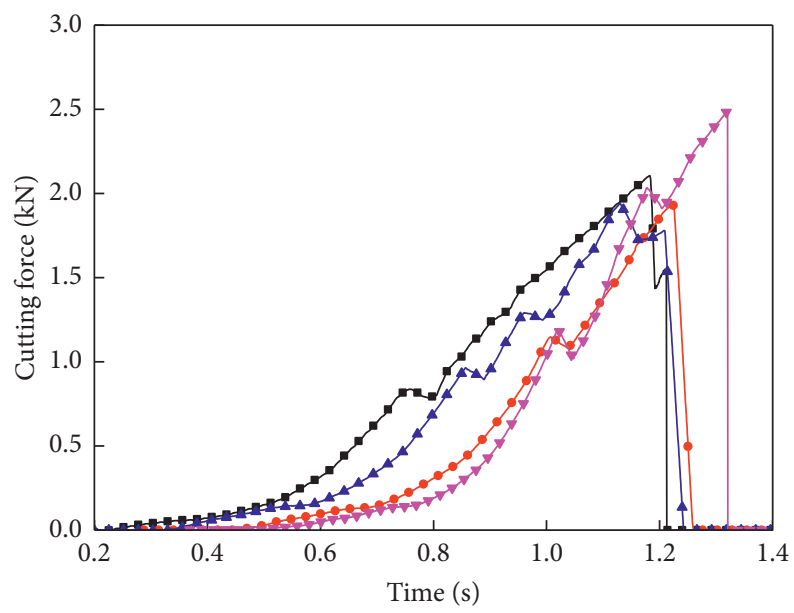

Width of rock plate

$\begin{array}{ll}\rightarrow & -500 \mathrm{~mm} \\ \rightarrow 400 \mathrm{~mm} & \rightarrow 200 \mathrm{~mm}\end{array}$

Figure 12: The cutting force for rock plates with different widths.

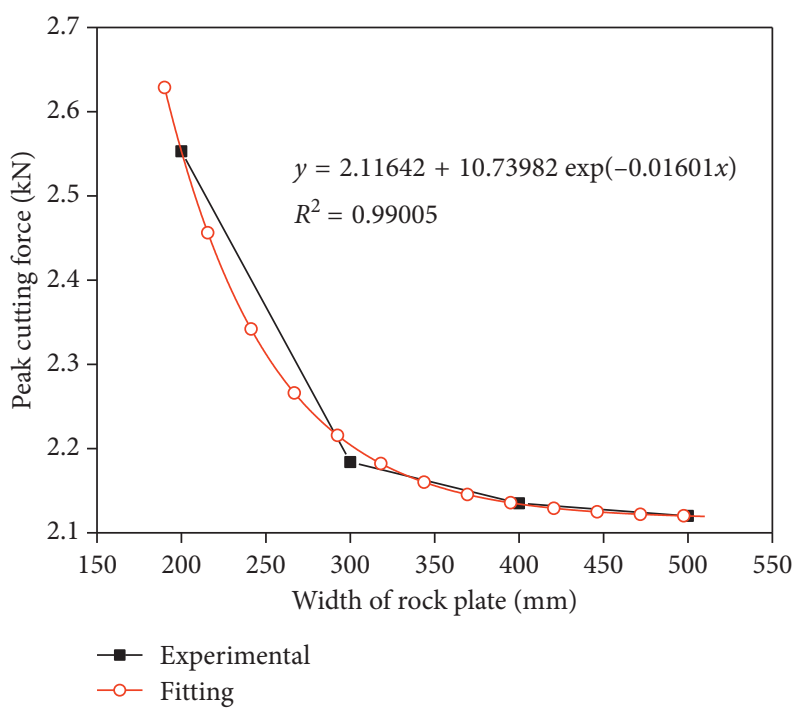

FIGURE 13: Variation of peak cutting forces at different widths.

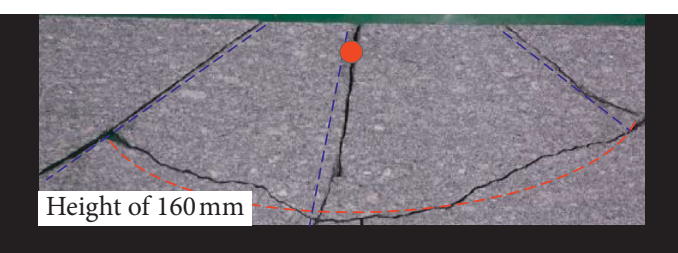

Fixed boundary

Cutting position

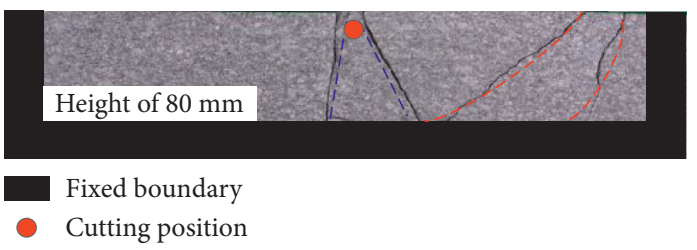

(b)

Figure 14: The experimental results for rock plates with different widths.

and also the rock fracture results are unsatisfactory. For improving the cutting efficiency, the situation of lower height of the rock plate should be avoided as far as possible and the height of the rock plate should be increased appropriately.
The bending strength of rock is directly related to the thickness of rock and has a great influence on the cutting force. Consequently, the influence of thickness on rock cutting performance is essential to research. At a thickness of $16 \mathrm{~mm}$ and $30 \mathrm{~mm}$, the cutting results are shown in 


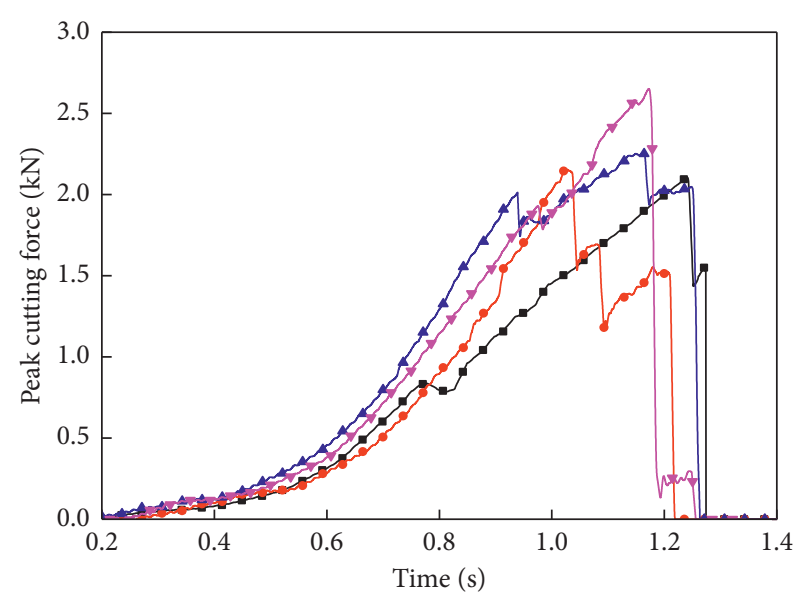

Height of rock plate

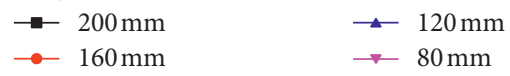

Figure 15: The cutting force for the rock plates with different heights.

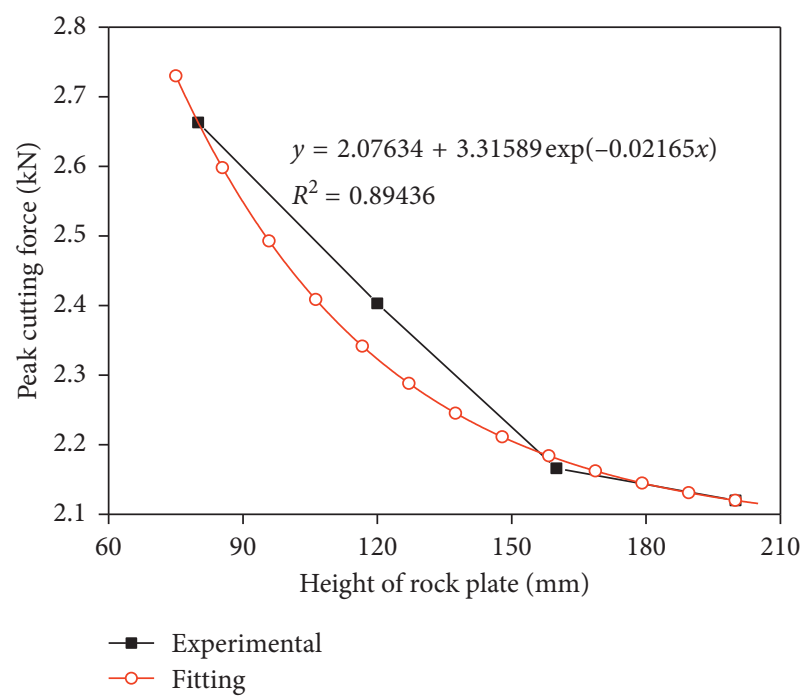

FIgURE 16: Variation of peak cutting forces at different widths.

Figure 17. For the lower thickness of $16 \mathrm{~mm}$, the fracture characteristics are similar to those in Figure 8. Great changes appeared for the higher thickness of $30 \mathrm{~mm}$ as presented in Figure 17(b), and part of the left rock plate remained on the base rock. As a result, the crushing area became smaller. The cutting force obtained from the experiment for rock plates with different thicknesses are shown in Figure 18, and it can be seen that the interval between the curves is clear and the peak cutting forces are significantly different.

The maximum and minimum peak cutting forces are obtained at thicknesses of $30 \mathrm{~mm}$ and $16 \mathrm{~mm}$, respectively, because the flexural strength enhanced with the enlarging thickness. Correspondingly, the cutting force increased steadily, as shown in Figure 19. From the varied amplitude of peak cutting force at different thicknesses, it can be concluded that the influence of thickness on peak cutting force is greater than that of width and height.
3.4. Cutting Depth Influencing Cutting Performance. In this paper, the cutting depth was defined as the distance from the top face of the rock plate to the cutting position of the conical pick. In the previous paper, the cutting depth of all experiments was $20 \mathrm{~mm}$. To research the influence of cutting depth on cutting performance, the experiments were conducted at $4 \mathrm{~mm}, 36 \mathrm{~mm}$, and $45 \mathrm{~mm}$. The experiment results at cutting depths of $36 \mathrm{~mm}$ and $45 \mathrm{~mm}$, as shown in Figure 20, are obviously different from those in Figures 8, 11,14 , and 17 . At the higher cutting depth, only half of the rock plate was broken, and the other half was intact. Moreover, greater cutting force was caused by the higher cutting depth, as show in Figure 21 according to the experiment. Therefore, higher cutting depth was not conductive to rock plate fragmentation. With the increase in cutting depth, the cutting force increased, as presented in Figure 22. The conical pick was closer to the bottom edge of the rock plate at higher cutting depth. In order to obtain the same bending moment with lower cutting depth, greater cutting force was required at higher cutting depth. Consequently, higher cutting depth should be prevented. On the contrary, the next research idea was suggested by this situation. The two sides free and two sides constraint rock plate was obtained. It is essential to study the rupture characteristics of the rock plate under such constraint.

3.5. Confining Pressure Influencing Cutting Performance. Many deep roadways are below the horizontal line of 1000 meters [32]. Lateral rock pressure has a certain influence on rock strength and then influence on cutting force. The simulation results at confining pressures of $1 \mathrm{MPa}$ and $4 \mathrm{MPa}$ are shown in Figure 23. More cracks generated and the size of rock fragments decreased when confining pressure increased to $4 \mathrm{MPa}$. Therefore, more fragments were obtained at a higher confining pressure. Originally, peak cutting force increased with the increasing lateral pressure; when it reached to the maximum at a lateral pressure of $2 \mathrm{MPa}$, it began to decrease with the increasing lateral pressure, as shown in Figure 24.

3.6. Relationship Analysis. As illustrated in Figures 10, 13, 16 , and 19, an exponential relationship emerged between UCS, physical parameters of the rock plate, and peak cutting forces. Similarly, the peak cutting force and cutting depth also have an exponential relationship, as presented in Figure 22. Besides, as seen in Figure 24, the peak cutting force and confining pressure have a binomial relationship. The regression analysis results are summarized in Table 3.

The correlation coefficients of $0.9998,0.8643,0.9905$, $0.9915,0.9953$, and 0.9981 demonstrates close relationships between peak cutting forces and cutting parameters. The confidence factor is a significant criterion for evaluating reliability of regression analysis results [33]. The confidence level of all numerical fittings in this paper is 0.95 , which requires the $\operatorname{prob}(P)$ value greater than $F$ value in statistics be less than 0.05; only in this way, the result is credible and has a significant difference. When the prob value is less than 


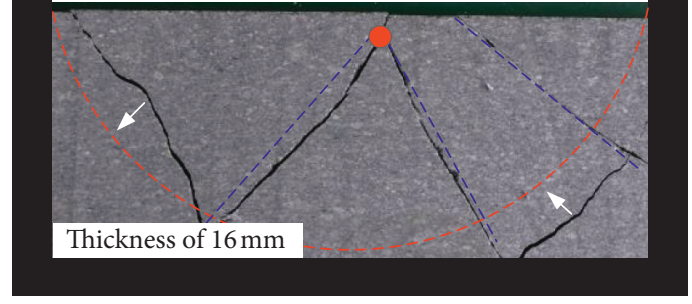

Fixed boundary

- Cutting position

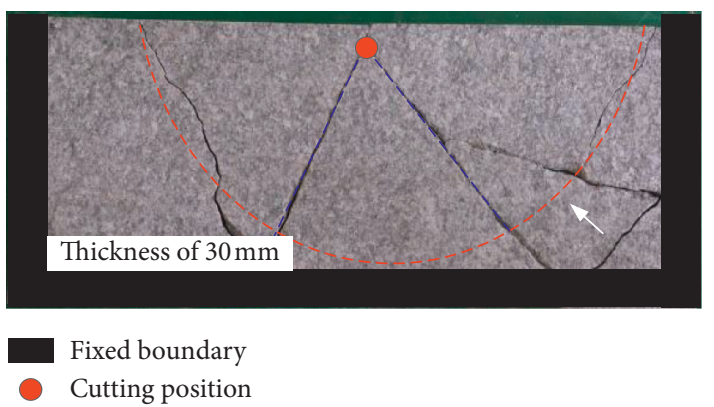

(b)

FiguRE 17: The experimental results for rock plates with different thicknesses.

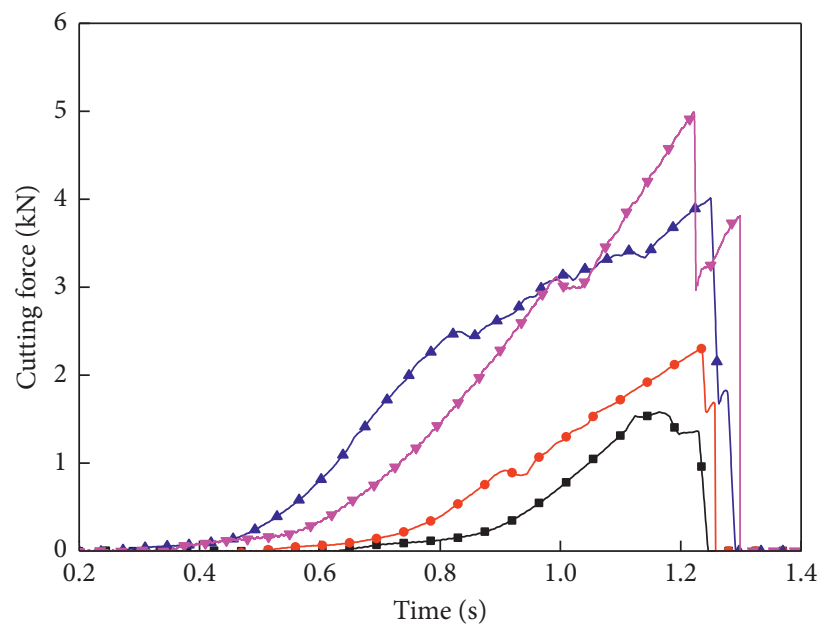

Thickness of rock plate

$\begin{array}{ll}\rightarrow-16 \mathrm{~mm} & \rightarrow 26 \mathrm{~mm} \\ \rightarrow-20 \mathrm{~mm} & \rightarrow 30 \mathrm{~mm}\end{array}$

Figure 18: The cutting force for rock plates with different thicknesses.

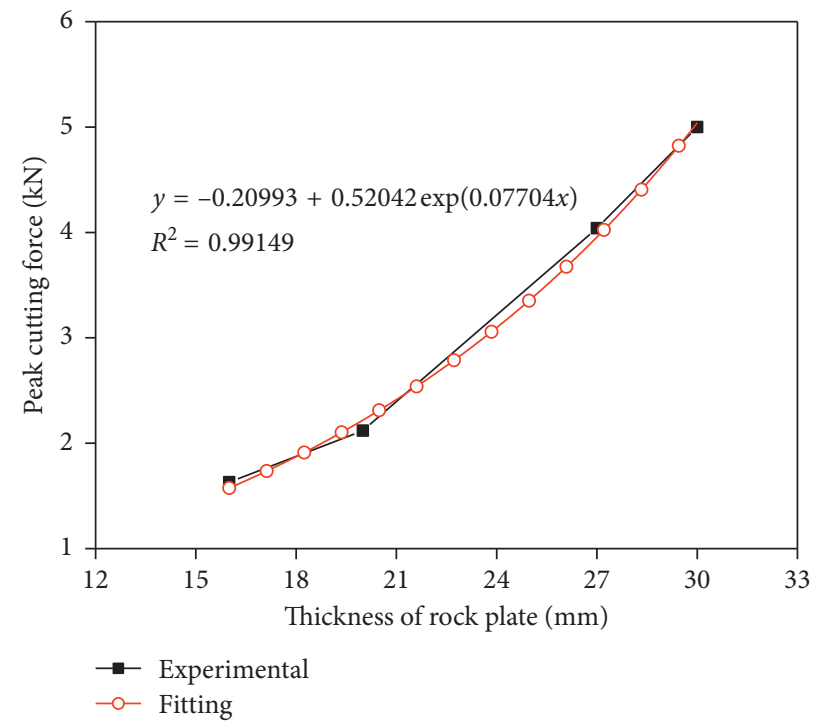

FIGURE 19: Variation of peak cutting forces at different thicknesses. 


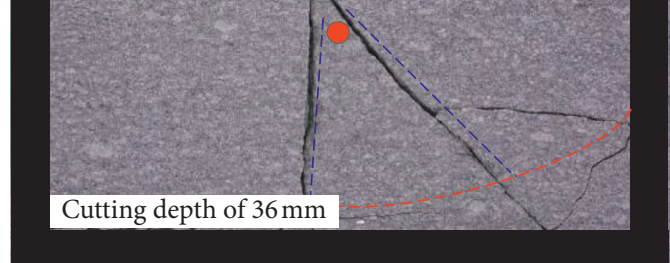

Fixed boundary

- Cutting position

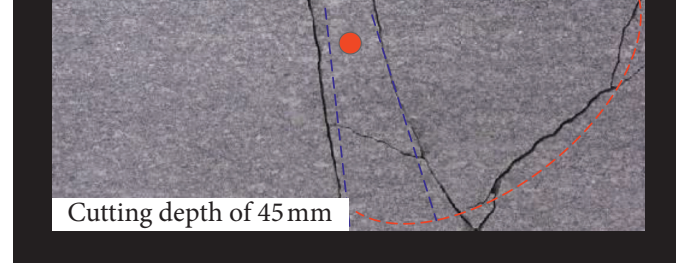

Fixed boundary

Cutting position

(a)

(b)

Figure 20: The experimental results for rock plates with different cutting depths.

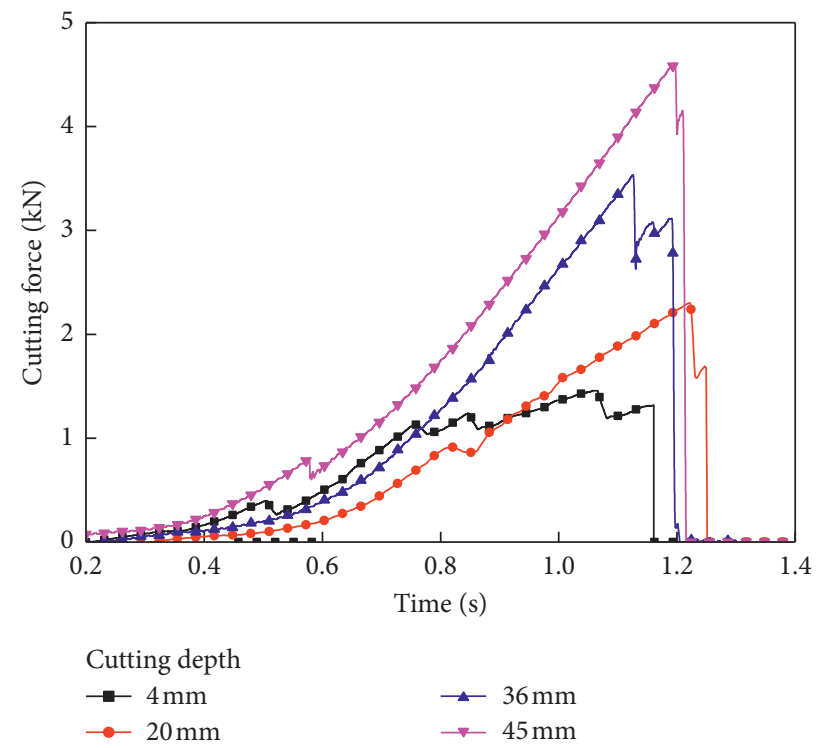

Figure 21: The cutting force for rock plates with different cutting depths.

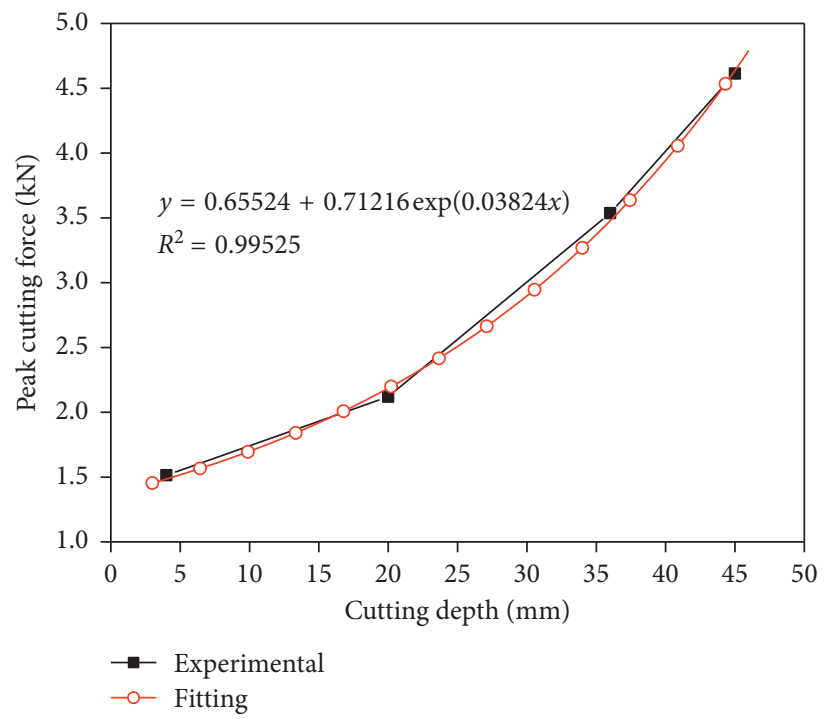

FIGURE 22: Variation of peak cutting forces at different cutting depths. 


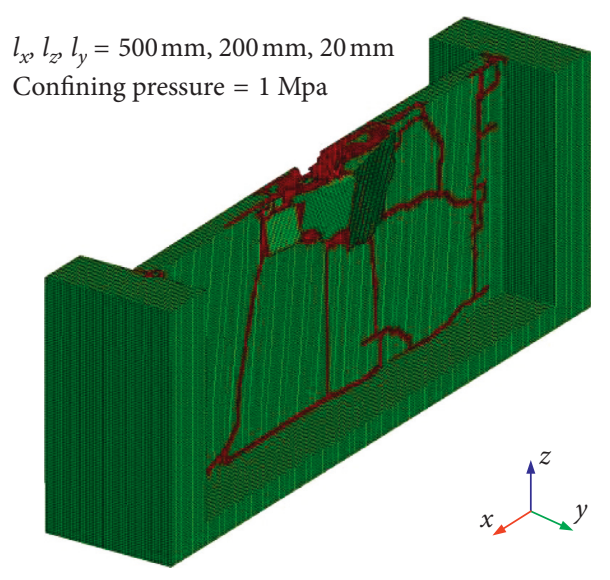

(a)

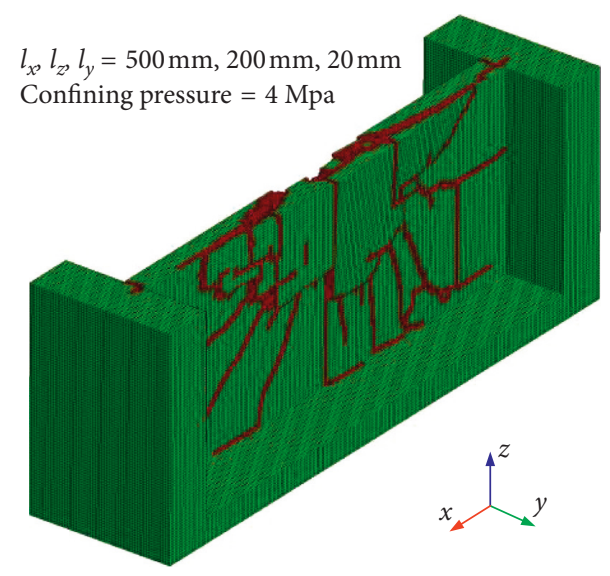

(b)

Figure 23: The numerical results at different confining pressures: (a) $1 \mathrm{MPa}$ and (b) $4 \mathrm{MPa}$.

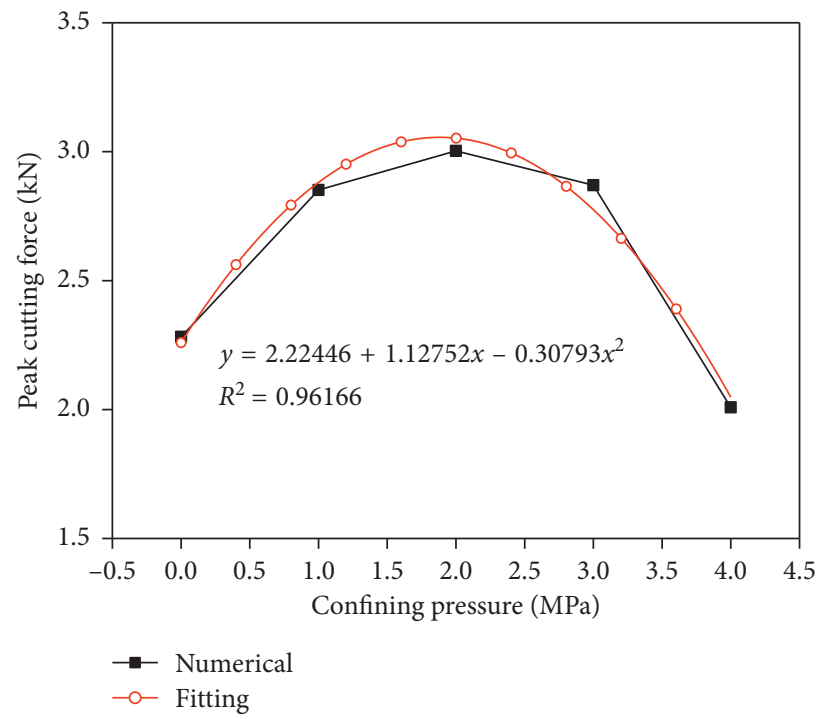

FIGURE 24: Variation of peak cutting forces at different confining pressures.

TABLE 3: The relationship analysis of peak cutting force.

\begin{tabular}{lccc}
\hline Variable & Relational expression & Correlation coefficient & $F$ value \\
\hline F-UCS & $y=1.19908+0.08203 \exp (0.20133 x)$ & 0.9998 & 87083 \\
F-width & $y=2.11642+10.73982 \exp (-0.01601 x)$ & 0.9905 & 16194 \\
F-height & $y=2.07634+3.31589 \exp (-0.02165 x)$ & 0.8643 & 1116 \\
F-thickness & $y=-0.20993+0.52042 \exp (0.07704 x)$ & 0.9915 & 751 \\
F-depth & $y=0.65524+0.71216 \exp (0.03824 x)$ & 0.9953 & 0.005 \\
F-confining & $y=2.22446+1.12752 x-0.30793 x^{2}$ & 0.9981 & 0.02 \\
\hline
\end{tabular}

0.01 , the fitting result is very significant. All $P$ values achieved in this paper are less than 0.05. It indicates the regression analysis results are credible and trustworthy.

\section{Conclusion}

A rock cutting method was proposed to overcome pick wear encountered in roadway tunneling. Rock cutting test beds were built for the purpose of research the cutting performance of the new cutting method. Both the experiments and the numerical simulations were carried out. A 3D FEM, which combines damage constitutive and erosion failure, was employed in this paper to study the rock plate cutting process. The main conclusions are as follows:

(1) The rock plate cutting process is presented in detail through the interaction model between the conical pick and the rock plate. During simulation, cracks generated and propagated and rock fragments separated from the base rock. Meanwhile, the fracture and peak cutting force obtained in numerical 
simulation were basically the same as that obtained in the experiments. Therefore, the 3D FEM is an effective method to simulate crack generation and fragment separation.

(2) The main fracture processes of the rock plate are as follows: (a) a main crack generated at the cutting position of the conical pick; (b) it then broke at the intersection between the fixed and free boundaries; and (c) with the displacement of the conical pick, the cracks expanded and the rock fragment separated from the base rock.

(3) Two main types of cracks appeared in the rock cutting experiment, one is the radial cracks generated from the cutting position, and the other is close to the circular arc along with the rock plate edge. Higher width and height are beneficial not only to fragmentation but also to cutting force.

(4) Peak cutting force variation was remarkable with the rock plate physical size and cutting parameters. The experimental results demonstrated that with the increased thickness and compressive strength of the rock plate, peak cutting force increased obviously. In contrast, peak cutting force reduced and then remained steady with the width and reduced with the height. Besides, the numerical simulation indicated that the peak cutting fore increased and then decreased with the confining pressure.

(5) The correlation coefficient achieved by fitting shows that close relevance exists between peak cutting forces and parameters. At the confidence level of 0.95 , the $P$ values obtained in regression analysis were all in accordance with the statistical requirement; hence, the fitting results were credible.

\section{Data Availability}

The data used to support the findings of this study are included within the article.

\section{Conflicts of Interest}

The authors declare that there are no conflicts of interest regarding the publication of this paper.

\section{Acknowledgments}

This work was supported by projects of the National Natural Science Foundation of China (Grant no. 51704178) and the Natural Science Foundation of Shandong Province (Grant nos. ZR2019BEE069 and ZR2019MEE067).

\section{References}

[1] X. Liu, P. Tang, X. Li, and M. Tian, "Self-rotatory performance of conical cutter interacted with rock material," Engineering Failure Analysis, vol. 80, pp. 197-209, 2017.

[2] S. Thomas, M. Antony, T. Dimitra, and R. Galler, "Hard rock cutting with high pressure jets in various ambient pressure regimes," International Journal of Rock Mechanics and Mining Sciences, vol. 108, pp. 179-188, 2018.

[3] L. Li, C. Tang, S. Tang et al., "Damage coupled thermo-mechanical model for rock failure process and applications," Chinese Journal of Theoretical and Applied Mechanics, vol. 38, no. 4, pp. 505-513, 2006.

[4] H. Jiang and D. Meng, "3D numerical modelling of rock fracture with a hybrid finite and cohesive element method," Engineering Fracture Mechanics, vol. 199, pp. 280-293, 2018.

[5] I. Evans, "Optimum line spacing for cutting picks," Mining Engineering, vol. 141, pp. 433-434, 1982.

[6] I. Evans, "A theory of the cutting force for point-attack picks," International Journal of Mining Engineering, vol. 2, no. 1, pp. 63-71, 1984.

[7] F. F. Roxborough and Z. C. Liu, "Theoretical considerations on pick shape in rock and coal cutting," in Proceedings of the Sixth Underground Operator's Conference, pp. 189-193, Kalgoorlie City, Australia, November 1995.

[8] R. M. Goktan, “A suggested improvement on Evans' cutting theory for conical bits," in Proceedings of the Fourth International Symposium on Mine Mechanization and Automation, vol. 1, pp. 57-61, Queensland, Australia, July 1997.

[9] C. Balci and N. Bilgin, "Correlative study of linear small and full-scale rock cutting tests to select mechanized excavation machines," International Journal of Rock Mechanics and Mining Sciences, vol. 44, no. 3, pp. 468-476, 2007.

[10] X. Wang, O. Su, Q. F. Wang, and Y.-P. Liang, "Effect of cutting depth and line spacing on the cuttability behavior of sandstones by conical picks," Arabian Journal of Geosciences, vol. 10, no. 23, p. 525, 2017.

[11] C. Dogruoz and N. Bolukbasi, "Effect of cutting tool blunting on the performances of various mechanical excavators used in low- and medium-strength rocks," Bulletin of Engineering Geology and the Environment, vol. 73, no. 3, pp. 781-789, 2014.

[12] Z. Niu, F. Jiao, and K. Cheng, "An innovative investigation on chip formation mechanisms in micro-milling using natural diamond and tungsten carbide tools," Journal of Manufacturing Processes, vol. 31, no. 1, pp. 382-394, 2018.

[13] W. Sawangsri and K. Cheng, "An innovative approach to cutting force modelling in diamond turning and its correlation analysis with tool wear," Proceedings of the Institution of Mechanical Engineers, Part B: Journal of Engineering Manufacture, vol. 230, no. 3, pp. 405-415, 2016.

[14] K. Cheng, Machining Dynamics: Theory, Applications and Practices, Springer, London, UK, 2008.

[15] J. Huang, Y. Zhang, L. Zhu, and T. Wang, "Numerical simulation of rock cutting in deep mining conditions," International Journal of Rock Mechanics and Mining Sciences, vol. 84, pp. 80-86, 2016.

[16] X. Y. Li, Y. G. Lv, and S. B. Jiang, "Effects of spiral line for pick arrangement on boom type roadheader cutting load," International Journal of Simulation Modelling, vol. 15, no. 1, pp. 170-180, 2016.

[17] X. Li, B. Huang, G. Ma, and Q. Zeng, "Study on roadheader cutting load at different properties of coal and rock," The Scientific World Journal, vol. 2013, Article ID 624512, 8 pages, 2013.

[18] L. Zhu, T. Wei, B. Liu, and T. Yu, "Simulation analysis of rock braking mechanism of tunnel boring machine," Tehnicki Vjesnik, vol. 23, no. 6, pp. 1585-1590, 2016.

[19] J.-Y. Park, H. Kang, J.-W. Lee et al., “A study on rock cutting efficiency and structural stability of a point attack pick cutter by lab-scale linear cutting machine testing and finite element 
analysis," International Journal of Rock Mechanics and Mining Sciences, vol. 103, no. 2018, pp. 215-229, 2018.

[20] Z. Lu, L. Wan, Q. Zeng, X. Zhang, and K. Gao, "Numerical simulation of rock plate cutting with three sides fixed and one side free," Advances in Materials Science and Engineering, vol. 2018, Article ID 5464295, 21 pages, 2018.

[21] M. C. Jaime, Y. Zhou, J.-S. Lin, and I. K. Gamwo, "Finite element modeling of rock cutting and its fragmentation process," International Journal of Rock Mechanics and Mining Sciences, vol. 80, pp. 137-146, 2015.

[22] Y. Zhou and J.-S. Lin, "Modeling the ductile-brittle failure mode transition in rock cutting," Engineering Fracture Mechanics, vol. 127, pp. 135-147, 2014.

[23] P. L. Menezes, M. R. Lovell, I. V. Avdeev, J.-S. Lin, and C. F. Higgs III, "Studies on the formation of discontinuous chips during rock cutting using an explicit finite element model," International Journal of Advanced Manufacturing Technology, vol. 70, no. 1-4, pp. 635-648, 2014.

[24] Y. Dai, L. S. Chen, and X. Zhu, "Modelling and simulation of a mining machine excavating seabed massive sulfide deposits," International Journal of Simulation Modelling, vol. 15, no. 2, pp. 377-387, 2016.

[25] O. Su and N. Ali Akcin, "Numerical simulation of rock cutting using the discrete element method," International Journal of Rock Mechanics and Mining Sciences, vol. 48, no. 3, pp. 434-442, 2011.

[26] Y. Shimizu, R. Hart, and P. Cundall, "Simulation of rock cutting using distinct element method-PFC2D," Numerical Modeling in Micromechanics Via Particle Methods, vol. 1, no. 4, pp. 63-72, 2004.

[27] J. P. Loui and U. M. Rao Karanam, "Numerical studies on chip formation in drag-pick cutting of rocks," Geotechnical and Geological Engineering, vol. 30, no. 1, pp. 145-161, 2012.

[28] M. Stavropoulou, "Modeling of small-diameter rotary drilling tests on marbles," International Journal of Rock Mechanics and Mining Sciences, vol. 43, no. 7, pp. 1034-1051, 2006.

[29] N. Innaurato, C. Oggeri, P. P. Oreste, and R. Vinai, "Experimental and numerical studies on rock breaking with TBM tools under high stress confinement," Rock Mechanics and Rock Engineering, vol. 40, no. 5, pp. 429-451, 2007.

[30] D. L. Yang, J. P. Li, L. P. Wang, K. D. Gao, Y. H. Tang, and Y. X. Wang, "Experimental and theoretical design for decreasing wear in conical picks in rotation-drilling cutting process," International Journal of Advanced Manufacturing Technology, vol. 77, no. 9-12, pp. 1571-1579, 2015.

[31] T. J. Holmquist, G. R. Johnson, and W. H. Cook, "A computational constitutive model for concrete subjected to large strains, high strain rates, and high pressures," in Proceeding of the Fourteenth International Symposium on Ballistics, pp. 110, Quebec City, Canada, September 1993.

[32] M. C. He, H. P. Xie, S. P. Peng, and Y.-D. Jiang, "Study on rock mechanics in deep mining engineering," Chinese Journal of Rock Mechanics and Engineering, vol. 24, no. 16, pp. 28032813, 2005.

[33] Z. G. Lu, L. R. Wan, Q. L. Zeng, X. Zhang, and K. Gao, "Numerical simulation of fragment separation during rock cutting using a 3D dynamic finite element analysis code," Advances in Materials Science and Engineering, vol. 2017, Article ID 3024918, 17 pages, 2017. 


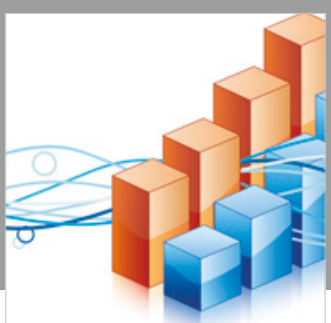

Advances in

Operations Research

\section{-n-m}
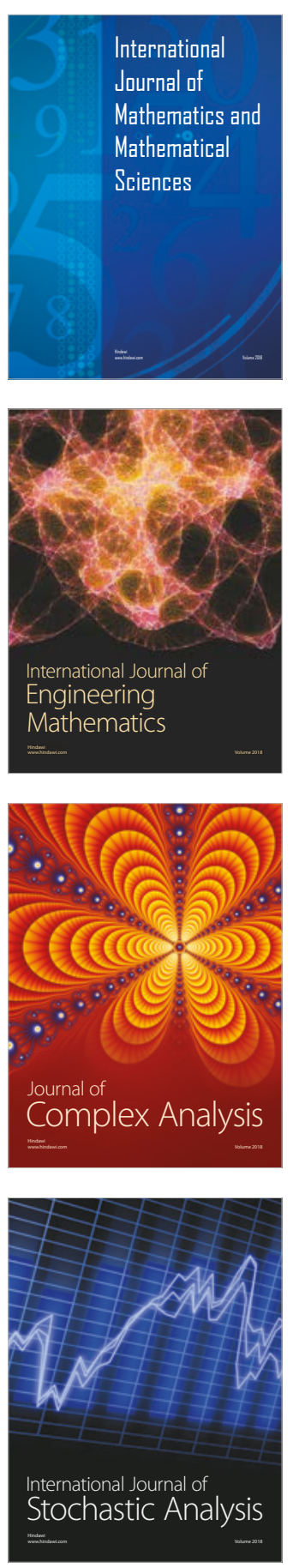
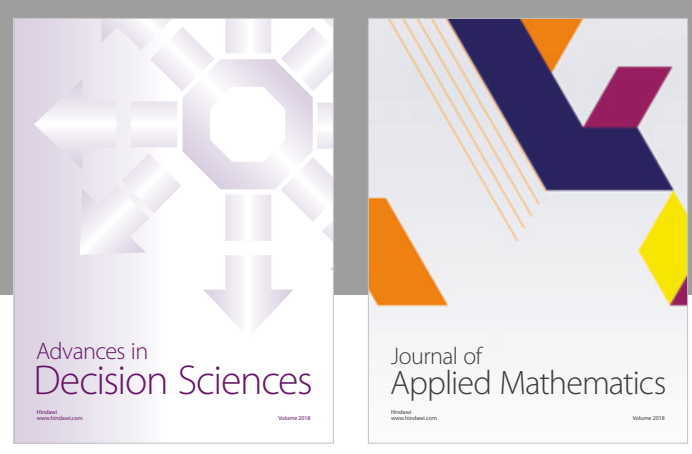

Journal of

Applied Mathematics
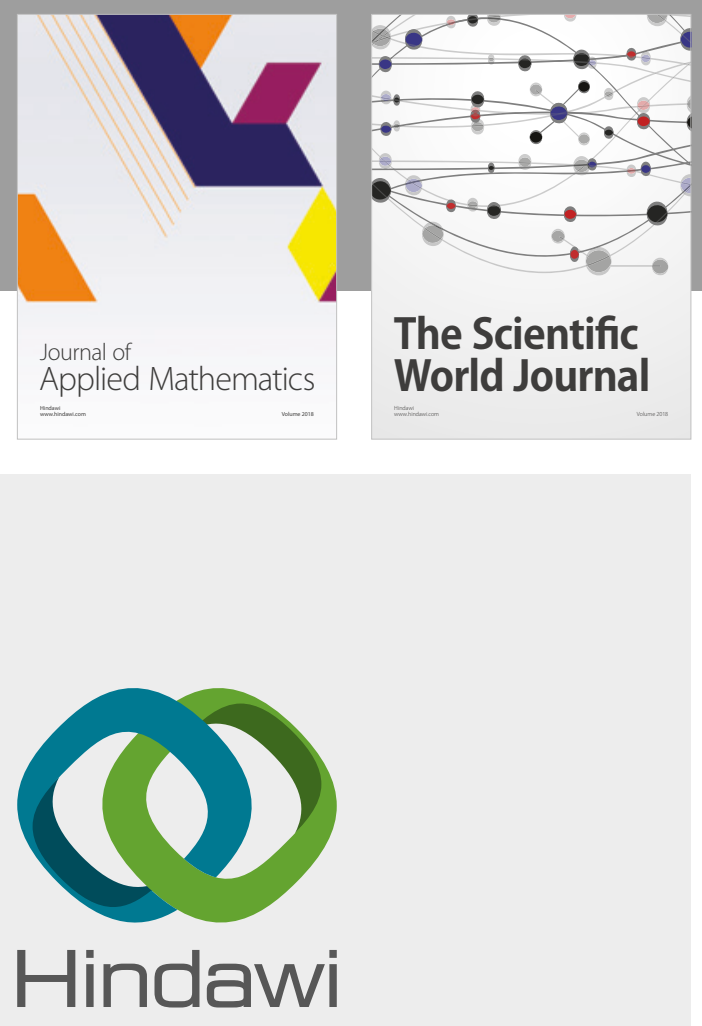

Submit your manuscripts at

www.hindawi.com

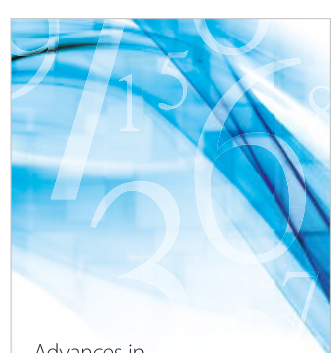

Advances in
Numerical Analysis
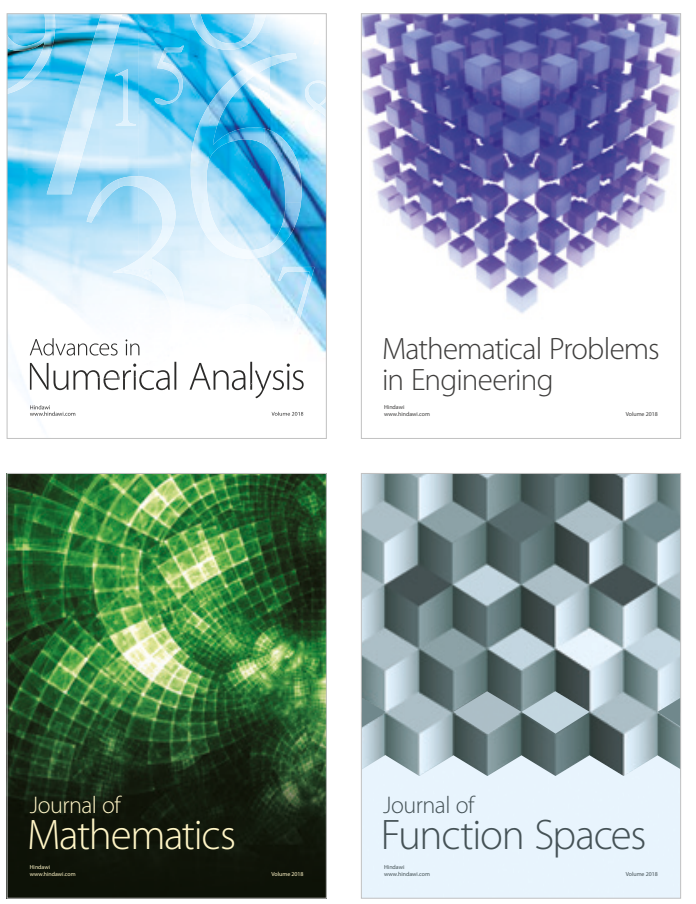

Mathematical Problems in Engineering

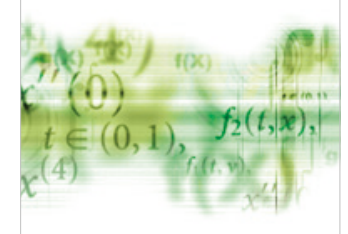

International Journal of

Differential Equations

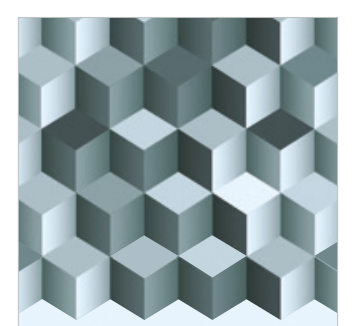

Journal of

Function Spaces

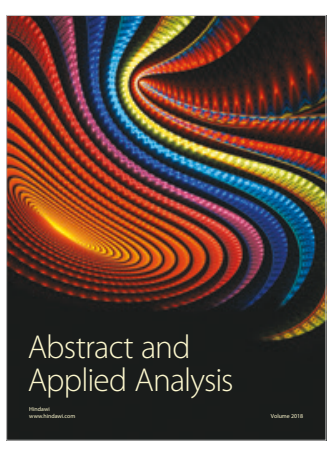

The Scientific

World Journal

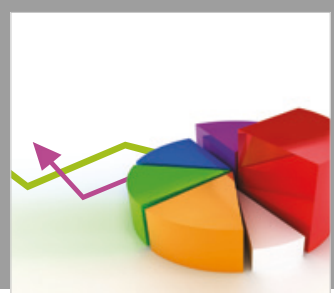

Journal of

Probability and Statistics
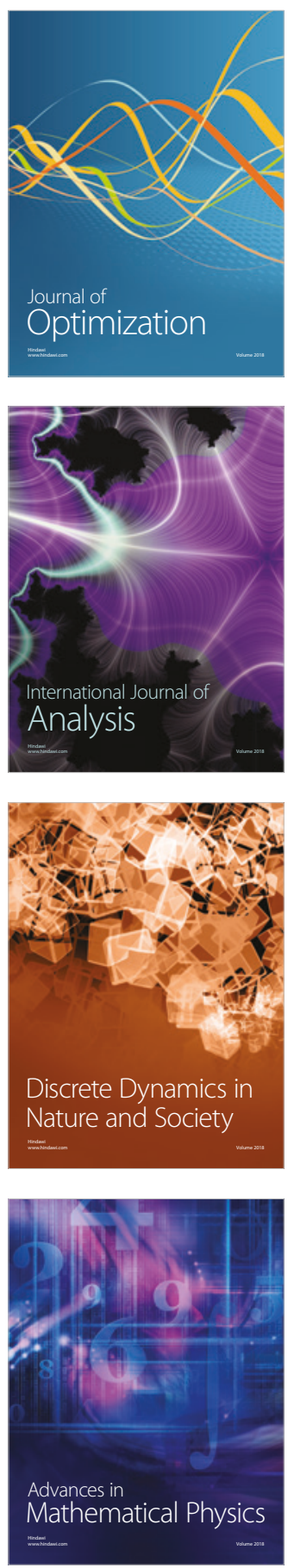